\title{
Un reto a la democracia: el gobierno de las áreas metropolitanas
}

Jordi Borja*

LA CIUDAD EUROPEA

\section{Ciudad y municipios}

$\mathrm{H}$ oy está de moda hablar de la ciudad en Europa. Estudios comparativos, rankings o jerarquías de ciudades, congresos sobre sistemas urbanos, ciudades globales... Pero, ¿de qué ciudad hablamos? Las realidades urbanas son múltiples y complejas. No podemos comparar, por ejemplo, los municipios estrictos de Roma (1507 km²) y Barcelona $\left(97 \mathrm{~km}^{2}\right)$. Si observamos la lista de las 400 ciudades europeas de más de 100000 habitantes nos encontraremos con ciudades centrales de una gran aglomeración, con ciudades periféricas de la ciudad central, otras son ciudades intermedias, etc. Las estadísticas y los rankings confunden sistemáticamente más que informan, bien porque comparan unidades administrativas que representan realidades urbanas diversas, bien porque utilizan ya realidades administrativas heterogéneas. Por ejemplo, en algunos informes europeos se compara el "Rhin-Rhur" con el municipio de Milán o Barcelona, o la aglomeración de Lille con un municipio francés cualquiera que sea centro de su aglomeración.

* Con la colaboración de Jordi Ventayol. Se publica con la autorización del autor. 
Al proponer políticas para la gran ciudad se debe tener en cuenta la existencia de todas estas realidades. La ciudad europea es, o tiende a ser, una realidad múltiple, policéntrica, discontinua. En ella pueden distinguirse, por lo menos, tres niveles: la ciudad-central, que muchas veces corresponde al municipio que da nombre a la ciudad y es su principal valor de cambio; la ciudad-metropolitana, aglomeración o continuo urbano, fenómeno europeo de crecimiento periférico en un tejido históricamente urbanizado y políticamente diferenciado y que representa hoy uno de los grandes retos de la ciudad real: la ciudad-región, o región metropolitana, es la ciudad visualizada como proyecto de futuro, el área real de planteamiento, de definición de grandes proyectos y de gestión de servicios básicos (transportes, agua, eliminación de residuos).

A pesar de esta realidad diversa y cambiante, ha prevalecido la fragmentación y el uniformismo administrativo, lo que dificulta el papel de la ciudad como ente político. La ciudad hoy no sólo debe ofrecer servicios. Debe planificar el territorio, ordenar el crecimiento, hacer urbanismo periférico, renovar su centro y construir infraestructuras de comunicación y económicas. Precisa de un territorio más amplio que el estrictamente municipal, donde sea posible el desarrollo económico, la promoción de la ciudad desde el punto de vista cultural y turístico, de atractivo y de competitividad en el mundo. Las grandes ciudades europeas, su sistema urbano, son nuestras multinacionales y el gobierno de la ciudad debe asemejarse a su consejo de administración. Las ciudades no sólo compiten entre sí. También, y muy especialmente, establecen redes de ciudades que permiten la transferencia de sus tecnologías, el intercambio de políticas urbanas, la innovación en los productos que ofrecen a sus ciudades.

Concurrencia y complementariedad, completar la ciudad, integrar a su población, convertir a los habitantes de la aglomeración, de la ciudad real, en ciudadanos de plenos derechos no es siempre tarea fácil, especialmente en Europa donde tenemos ciudades con el 20-25\% de población no comunitaria, sin los derechos políticos elementales. Por otra parte, la lógica de la competencia lleva unida la lógica de dualización social, aunque en algunas ciudades hayamos podido contener esta tendencia.

Tres son, básicamente, los problemas con que nos encontramos al abordar esta visión de la ciudad: 1) fragmentación administrativa, 2) insuficiencia a nivel competencia y de recursos y 3) falta de un proyecto global para la ciudad real.

1) La fragmentación administrativa la conocemos bien en España, Italia y otros países de Europa. Si tomamos el ejemplo del área de Barcelona, en una superficie de $1000 \mathrm{~km}^{2}$, todavía más pequeña que el municipio de Roma, nos encontramos con una población de 3500000 habitantes sobre los que actúan 60 o 70 municipios, 4 o 5 entes intermedios entre la provincia y el municipio, la provincia, la región, los diferentes ministerios estatales, organismos y empresas públicas, etcétera. 


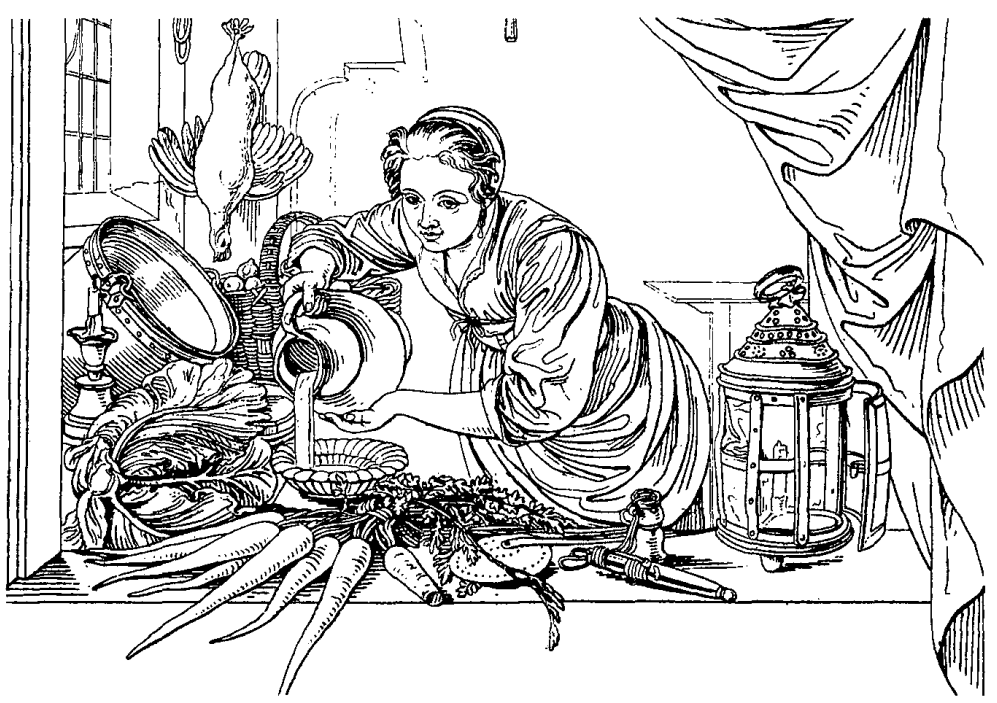

2) A la fragmentación administrativa se le une la insuficiencia e inadecuación de competencias y recursos. Somos todavía esclavos de una visión administrativa, jerárquica, de los niveles de competencia: sólo a los municipios les quedan competencias de tipo residual o que no pueden ser gestionadas por escasez de recursos.

3) En tercer lugar, sumado a la falta de un ente político-administrativo para todo el ámbito de la ciudad real, somos herederos en los años 90 de la crisis de la cultura de la planificación, lo que nos ha llevado a una falta generalizada de proyectos colectivos de desarrollo y equilibrio para todo el territorio.

Frente a este tipo de problemas, las propuestas que se barajan desde gobiernos locales e instituciones son variadas.

Primero, simplificación administrativa (y yo añadiría no crear más estructuras territoriales ni discutir sobre sus límites físicos, aprovechar las ya existentes y, si es posible, suprimir alguna).

Segundo, no iniciar una batalla a nivel de competencia y de recursos, sino establecer un consenso estratégico sobre territorio que posibilite contratos o conciertos interadministrativos y de cooperación públicoprivada a partir de este consenso. 
Tercero, tomar conciencia del valor de cambio y simbólico de la ciudad para atribuir estos valores al territorio más amplio posible. Sólo así se podría construir la ciudad futura, que es la ciudad-región, la ciudadmetropolitana futura.

En definitiva, las soluciones en Europa son múltiples pero nos encontramos en un momento de gran confusión. Sólo tres ejemplos: en Francia, el caso de París. Todos se ocupan de París (el primer ministro, el Ministère de l'Equipement y la región), incluso el gobierno de la ciudadcentral. Pero no se define ningún proyecto básico consensuado y, lo que es peor, no se consigue tan sólo establecer un marco político-legal legitimado para acordar esta definición. Segundo ejemplo de confusión, Italia, donde se elabora una ley muy interesante sobre la ciudad metropolitana pero nadie sabe exactamente cómo será esa ciudad metropolitana, sus ámbitos, sus competencias. Tercer ejemplo, España, donde la restitución de las instituciones autonómicas regionales ha provocado la desaparición de las estructuras de coordinación metropolitana, vistas por las Comunidades Autónomas como un contrapoder (incluso cuando el mismo partido gobierna en los dos ámbitos, como es el caso de Valencia y Bilbao).

\section{Europa, ciudades y regiones}

La Europa de los noventa y la del próximo siglo es la Europa de las ciudades, un sistema urbano.

Las grandes aglomeraciones urbanas constituyen ya hoy un vasto tejido territorial que concentra la mayor parte de la población europea. Más del $50 \%$ vive en zonas altamente urbanizadas o regiones metropolitanas.

Pero no sólo la población se concentra en las grandes áreas urbanas. También en ellas se concentran a la vez el mayor potencial de desarrollo y los más graves problemas sociales, la riqueza y la desigualdad, el bienestar y los desequilibrios, las actividades más dinámicas e innovadoras y la marginalidad, coexisten en la ciudad metropolitana.

Las grandes ciudades, tanto en España como en Europa, han vivido un espectacular crecimiento urbano y demográfico durante los últimos treinta años y ello ha provocado la existencia de grandes déficits en equipamientos y servicios.

A pesar de dichos déficits, las grandes aglomeraciones urbanas son el motor del desarrollo económico y social, de las actividades lúdicoculturales, de la innovación tecnológica y de los centros del poder político.

Las grandes ciudades generan dinámicas y relaciones funcionales de tal magnitud, que rompen y dejan obsoletos los viejos esquemas administrativos. Hoy, "ciudad" y "municipio" son conceptos distintos.

No existe pues, una correlación entre la realidad social, económica, 
cultural y territorial generada por las dinámicas urbanas y las estructuras territoriales que el derecho administrativo tiene establecidas.

La población, el territorio y la organización, como elementos cuya existencia clara y definida, son presupuesto previo al reconocimiento del municipio como realidad jurídica, no tienen en las grandes ciudades el mismo valor, bien porque no existe organización que institucionalice la gran ciudad o bien porque su territorio tiene límites imprecisos o porque la población de la misma no es sólo la que reside en ella sino también la que usa la gran ciudad para sus actividades de ocio, culturales, de trabajo, etcétera.

La gran ciudad de la que estamos hablando es una realidad territorial que el derecho no contempla. Es una ciudad plurimunicipal que sobrepasa incluso las estructuras supramunicipales existentes y cuyo municipio central, por su dimensión y dinamismo, suele ejercer competencias en concurrencia con los organismos regionales y provinciales.

Es por ello que, para reglamentar su funcionamiento, se hace preciso establecer un cultura y una normativa jurídica que regule las relaciones interadministrativas y que compense el déficit democrático que se produce en la gran ciudad al no corresponderse las estructuras representativas con las áreas de vida social (por ejemplo, los habitantes de las periferias reciben las consecuencias de las decisiones de la ciudad central, de la cual hacen uso, pero sin votar en ella, de la misma forma que el gobierno de ésta no puede esperar su apoyo aunque tenga en cuenta los intereses de los usuarios periféricos).

La gran ciudad europea es una realidad multidimensional: ciudad central, aglomeración o continuo urbano y región metropolitana.

Pero además, la ciudad europea proyecta sus potencialidades hacia ámbitos superiores, transnacionales, en competencia y cooperación con las demás para atraer flujos de inversión de capitales, ferias, turismo cultural, etc., en un doble proceso de city-marketing y de red urbana o sistema de ciudades desconocido hasta hace pocos años.

Tampoco el derecho contempla el marco legal de este fenómeno en virtud del cual las ciudades actúan conjuntamente en regiones transfronterizas.

Esta ciudad real, multimunicipal, carece de una estructura representativa. Por contra está formada por una suma casi siempre inconexa de instituciones locales que generan una gran complejidad políticoadministrativa, creando al propio tiempo confusión, retrasos, opacidad e irresponsabilidad.

La gran ciudad, pues, se relaciona, hacia dentro y hacia fuera, constituyendo un verdadero sistema, tejiendo una espesa red de concurrencias, colaboraciones y competencias con otras ciudades que constituyen todas 
ellas el espacio en el que la ciudad se desarrolla como una gran unidad funcional, todo ello en el marco de un sistema europeo de ciudades.

En Europa hay regiones fuertes, dinámicas, emprendedoras y regiones desarticuladas. Las regiones fuertes fundamentan su empuje en una capital -gran ciudad- o en una conurbación muy integrada que actúan como motores de arrastre de la región.

Pero la simbiosis región-ciudad no es siempre fácil ni pacífica. Más allá de las posibles orientaciones políticas diversas, incluso enfrentadas, de los gobiernos regionales y municipales hay razones objetivas para el posible conflicto. Las áreas urbanas tienden a funcionar como una gran ciudad. Es la ciudad real, la ciudad de ciudades o la ciudad metropolitana.

En esta ciudad metropolitana, el municipio central tiende a extender su campo de actuación hacia los municipios de la llamada primera corona metropolitana para abordar en común prestaciones de servicios (como el transporte público, el tratamiento y la eliminación de residuos, el abastecimiento y el saneamiento de agua, etc.), la realización y/o instalación de grandes infraestructuras y equipamientos (aeropuertos, parques tecnológicos, puertos, polígonos industriales, etcétera).

De la misma forma, la ciudad metropolitana tiende a proyectarse hacia el espacio regional, hacia las segundas y terceras coronas, donde convive con otras ciudades, centros a su vez de otros espacios subregionales.

Pero como decíamos antes, su expansión no se detiene en el espacio regional, sino que se proyecta hacia el exterior para convertir la gran ciudad en uno de los centros de macrorregiones transfronterizas (estas macrorregiones suelen ser multipolares aunque haya una ciudad más dominante que otras).

Las regiones por su parte, en un proceso expansivo paralelo al de las grandes ciudades, quieren asumir un protagonismo en la Europa de hoy que conlleve su reconocimiento político específico.

Evidentemente, estos procesos expansivos provocan costos y tensiones con los demás municipios del continuo urbano y con los gobiernos regionales.

Dentro de este marco, cualquier política sistemática de enfrentamiento es un grave error que tarde o temprano provocará fracasos para todos y perjuicios para los ciudadanos. La realidad es más tozuda que las voluntades y la única forma de solventar los inevitables conflictos entre las diversas instituciones e instancias es el camino del consenso territorial, la colaboración institucional y la cooperación interadministrativa. 


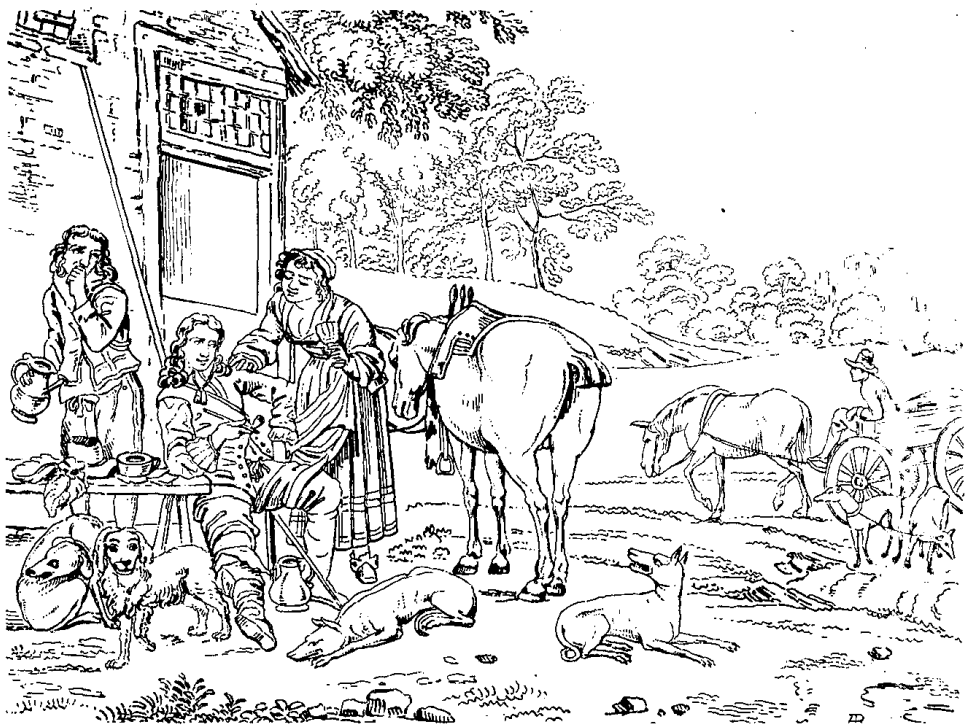

\section{ÁREAS METROPOLITANAS, CIUDADES Y MUNICIPIOS EN ESPAÑA}

\section{Una bistoria inacabada}

En la frontera del año 2000 casi dos terceras partes de los españoles viven en ciudades de más de 50000 habitantes. Lo urbano adquiere así una enorme y vital trascendencia económica, social, cultural y política.

El municipio, los municipios, como picza básica de la organización político administrativa del territorio español no se adapta en muchos casos a la realidad urbana. Este hecho se produce de forma evidente en las áreas metropolitanas.

La historia contemporánea española relativa a las áreas metropolitanas es breve e inacabada. El problema clave de las grandes aglomeraciones urbanas es su fragmentación político-administrativa y la dificultad de crear con éxito entidades supramunicipales-metropolitanas-capaces de gestionar en común los intereses supramunicipales de los municipios que las integran.

En 1960 el Ministerio de la Vivienda realizó un estudio en el que 
se definían 200 áreas metropolitanas españolas con dimensiones y características diversas, pero que constituían verdaderas aglomeraciones urbanas.

En 1970 y en ocasión del III Plan de Desarrollo se establecieron, a efectos estadísticos, 30 áreas metropolitanas. De ellas, 24 lo eran en proceso de desarrollo y por tanto, objeto de análisis y estudio, y las restantes (Madrid, Barcelona, Bilbao, Sevilla, Valencia y Zaragoza) a efectos de actuaciones que, hay que reseñar, no se llevaron a cabo.

Sin embargo, todos estos estudios y propuestas únicamente desembocaron en algún tipo de organismo metropolitano en Madrid, Barcelona, Valencia y Bilbao. En todos los casos, el origen de dichos organismos estuvo en la Administración Central y por tanto, no tenían carácter local. Su final ha sido, si bien por caminos y experiencias distintas, la desaparición.

El proceso de planificación e institucionalización de las áreas metropolitanas españolas como entidades locales, sólo encontró una formulación clara en Barcelona con la creación en el año 1974 de la entidad municipal metropolitana de Barcelona (Corporación Metropolitana de Barcelona).

El origen de la Corporación Metropolitana de Barcelona hay que buscarlo en la revisión del Plan Comarcal de 1953 por parte de una Comisión Técnica creada al efecto. Es en el seno del debate de dicha comisión cuando aparece por primera vez, explícitamente formulado para el caso de Barcelona, el concepto de área metropolitana.

A lo largo de veinte años se irá gestando un órgano de gesttión del área metropolitana. En mayo de 1974 se aprueba inicialmente el Plan General Metropolitano de Barcelona y su comarca y en el mes de agosto del mismo año se publica, el Decreto-Ley de creación de la Corporación Metropolitana de Barcelona (CMB) y se crea también la Comisión Provincial de Urbanismo para el resto del territorio provincial. Dicho Decreto-Ley configura la CMB como un organismo dependiente en cierto modo de la Administración Central, ya que su presidente es nombrado por el Consejo de Ministros y el nombramiento del gerente corresponde al ministro de Gobernación.

No será hasta las primeras elecciones municipales democráticas (1979) cuando el nuevo marco político condicionará, con base en la propia ley de elecciones locales, la estructura representativa de la CMB. Desde el primer momento, la propia institución, consciente de la necesidad de transformarse en una entidad plenamente local, introduce reformas en la propia estructura para ser más y más democrática. Así el presidente pasa a ser elegido por los consejeros metropolitanos, a su vez representantes elegidos democráticamente en sus municipios, y el gerente es nombrado por el propio Consejo metropolitano.

En el año de 1984 la cMB plantea ante el Parlamento catalán un proyecto para una mejor organización democrática de la institución que refleje 
la proporción, entre habitantes y representantes elegidos, solicitando aclemás la incorporación de todos los alcaldes del ámbito metropolitano.

En 1985 por primera vez en la legislación local española y a través de la Ley $7 / 85$ de 2 de abril, reguladora de las Bases del Régimen local, se configura legalmente el concepto de área metropolitana. Con anterioriclad a dicha ley únicamente algunos Estatutos de Autonomía habían previsto su existencia como entidad local (art. 5,2 del de Cataluña; art. 6, 3 de $\Lambda$ sturias, art. 46,3 de Valencia).

En Valencia, la Ley 12/96 de 31 de diciembre de las Cortes Valencianas, crea una estructura metropolitana local e imagen de la Corporación Metropolitana de Barcelona, el Conscll Metropolitá de l'Horta, pero que no tiene resuelto el tema de su financiación, por lo que su existencia ha devenido una mera virtualidad.

No obstante y volviendo al caso de Barcelona, el Parlamento de Cataluña aprobó en el año de 1987 una ley en virtud de la cual se suprimió la Corporación Metropolitana de Barcelona, se abrió un proceso de comarcalización del área metropolitana y se procedió a la creación de entidades funcionales especializadas y con ámbitos territoriales distintos (la Entidad Metropolitana del Transporte y la Entidad Metropolitana de Servicios Hidráulicos y del Tratamiento de Residuos).

Paralelamente en Sevilla y el área central de Asturias se ha iniciado un camino de metropolitanización light o estimulante, consistente en la emisión por parte de las Consejerías de Política Territorial de las respectivas Comunidades Autónomas, de directrices de coordinación territorial y colaboración intermunicipal.

\section{¿Por qué no se crean estructuras metropolitanas?}

Dos fenómenos de muy distinta naturaleza han contribuido decisivamente a la detención de este tímido proceso de metropolitanización:

a) La democratización política, la construcción del Estado de las Autonomías y la existencia de los ayuntamientos democráticamente elegidos. Las Comuniclades Autónomas asumen las competencias de la organización territorial y el plancamiento urbano. La revalorización de la autonomía local y la legitimidad y el celo de los nuevos municipios democráticos, junto con el lógico afán de protagonismo y de consolidación política del conjunto del territorio por parte de las Comunidades Autónomas provocan un serio cuestionamiento de la institucionalización metropolitana.

b) El estancamiento demográfico y económico de las grandes ciudades $y$ su entorno inmediato. El crecimiento se da en todo caso en la corona metropolitana y no requiere una ordenación global con la misma urgencia que antes. Las nuevas prioridades de la política local (actuación urbanística 
sobre el tejido urbano existente, equipamientos y servicios para los ciudadanos, reforma administrativa y modernización de la gestión pública) corresponden al municipio. Los problemas sociales y económicos más importantes, sin embargo -reactivación económica y creación de empleo, seguridad pública y protección ciudadana) superan las competencias y los medios municipales; pero al no existir estructuras metropolitanas fuertes que puedan recabarlos para sí, quedan teóricamente en manos de las administraciones centrales o autonómicas a pesar de su fuerte componente y dimensión local. Un proceso similar se da en los servicios típicamente metropolitanos (infraestructuras de comunicaciones y cconómicas, agua y saneamiento, transportes, vivienda) que quedan en manos de las políticas sectoriales regionales o estatales o de los impulsos de la ciudad central (Madrid puede ser la excepción por el carácter de región metropolitana de la Comunidad Autónoma).

\section{Efectos de las "áreas no metropolitanas"}

El resultado práctico de la no metropolitanización ha significado:

a) La hipertrofia institucional sobre el territorio metropolitano (administración del Estado, autonómica, provincial, metropolitana especializada, comarcal, municipal, más todas aquellas otras instituciones que intervienen decisivamente sobre el territorio como son, el puerto, la feria, el aeropuerto, los ferrocarriles, etcétera).

b) La descoordinación de las actuaciones públicas, consecuencia de la multiplicidad de instituciones, empresas públicas, agencias especializadas, etc , que operan sobre el territorio, lo cual ha comportado la pérdida de la visión globalizadora tan necesaria en territorios tan densamente ocupados.

c) La sectorialización de las políticas territoriales de ministerios, organismos autónomos, consejerías y empresas públicas no integradas en un planeamiento estratégico territorial metropolitano.

d) La pérdida de recursos financieros procedentes de la Administración Central sin que el gobierno autonómico los haya suplido (hay que tener presente además que la ley catalana de creación de las dos entidades metropolitanas especializadas, citadas anteriormente, no prevé su sistema de financiación).

e) La pérdida de competencias municipales que han sido asumidas por el gobierno autónomo (la aprobación definitiva de los planes parciales y especiales, incluso de la ciudad de Barcelona, corresponde a la Generalitat de Catalunya.

f) La desaparición de determinadas especificidades legales para el conjunto metropolitano vuelve a someter a los municipios a la regulación legal uniforme que no distingue la diversidad de problemáticas existentes entre pequeños y grandes municipios. 


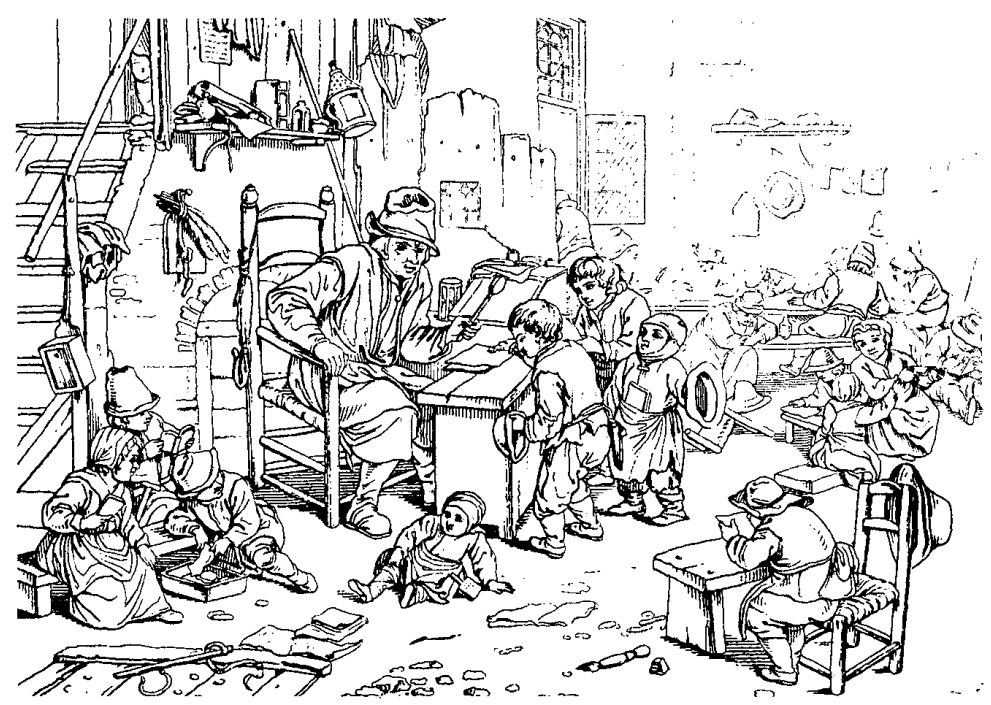

g) Finalmente los efectos del déficit democrático al que antes aludíamos en el sentido de que el gobierno de la ciudad central es elegido única y exclusivamente por los habitantes de su término municipal, cuando es evidente que la ciudad central es utilizada diariamente por miles de ciudadanos de su área metropolitana y además las decisiones que adopta el gobierno de ésta afectan de forma notoria a sus ciudades vecinas.

\section{Razones para la acción}

Frente al desajuste entre la realidad territorial, económica y funcional de las áreas metropolitanas y la realidad político-administrativa municipal, hay que plantearse tres niveles de actuación. 1) El primero es el del proceso de institucionalización del área metropolitana y de la planificación territorial y estratégica de su región de influencia. 2) El segundo se corresponde con el proceso de organización de la gestión conjunta de servicios y actuaciones en el continuo urbano. 3) Y el tercero consiste en el proceso de descentralización interno que es preciso efectuar para favorecer la participación cívico-ciucladana facilitando en consecuencia la identificación y la cooperación ciudadana. 


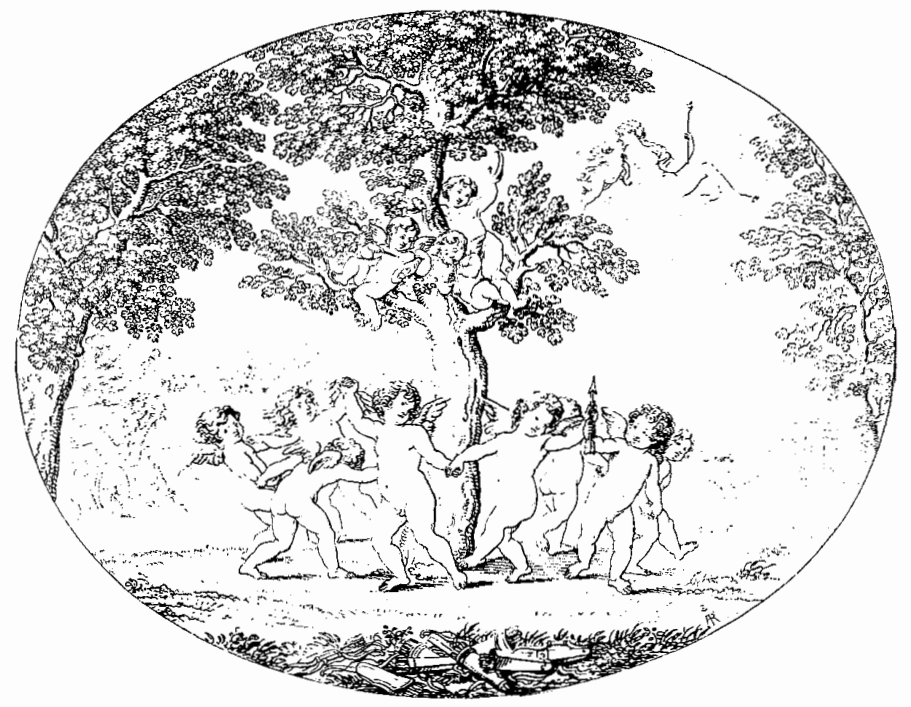

La situación actual exige, urgentemente, adoptar medidas y decisiones para las grandes ciudades y las áreas metropolitanas. Todos los elementos apuntan a que, en los próximos años, van a agudizarse las tensiones y desequilibrios territoriales urbanos.

Estamos en el inicio de una nueva fasc de desarrollo que requiere políticas muy activas y estructuras administrativas adlecuadas para realizarlas.

Después de los años de gran crecimiento demográfico (1955-1975) y de la década de estancamiento (1975-1985), el crecimiento de los últimos años presenta elementos comunes en las difercntes grandes ciudades y áreas metropolitanas:

a) En las áreas centrales de las grancles ciud. tes se da un doble proceso de disminución del crecimiento demográfico (incluso en algunos casos un retroceso aparente debido a la no contabilización de población ilegal) y de gran desarrollo del crecimiento urbano. La población residente no crece pero utiliza más la ciudad, al tiempo que se produce un crecimiento de la población flotante no residente que utiliza la ciudad central por motivos de trabajo, estudios, ocio, servicios o equipamiento.

b) En las áreas centrales de las grandes ciudades crece la demanda 
de locales comerciales, oficinas y equipamientos y aumenta, por tanto, la actividad del sector terciario, así como las demanndas de mayor calidad de vida por parte de los residentes. Ello implica, para los gobiernos locales, la necesidad de efectuar una adecuada combinación estratégica para hacer frente a las demandas tendientes al desarrollo de medidas para favorecer el atractivo del centro y las que tiendan a mejorar las condiciones de vida de la población residente evitando la definitiva terciarización de dichos espacios urbanos.

c) Las ciudades de la primera corona metropolitana viven crecimientos demográficos moderados, fruto sobre todo del crecimiento vegetativo de su propia población; mientras que en las segundas coronas se produce un mayor auge demográfico que conducirá inevitablemente a la ampliación de las conurbaciones y a la consolidación del fenómeno denominado ciudad-región.

d) En las ciudades de la periferia metropolitana se producen intensos procesos de consolidación de personalidades propias, compatibles con el gran poder de atracción del área central como imagen de marca de la aglomeración; pero capaces de generar como tales nuevos puntos de centralidad y atracción para los propios ciudadanos de estas ciudades, así como para los de su entorno inmediato, favoreciéndose así la consolidación de nuevas centralidades que configuran a la ciudad metropolitana como una ciudad morfológicamente policéntrica y polivalente.

Diez años después de haberse iniciado el proceso democrático y de haberse paralizado el de institucionalización de las áreas metropolitanas, conviene retomar la cuestión, aunque sin el propósito de implantar modelos uniformistas.

No todas las áreas metropolitanas tienen igual dimensión, población y número de municipios, ni las mismas características ni especificidades.

Las características especiales de Madrid (Madrid e's. aglomeración; Comunidad Autónoma $v$ 's. región metropolitana) permiten que la dirección de la macropolítica metropolitana (planteamiento territorial y estratégico) y el impulso de la solidaridad y coordinación intermunicipal sean asumidos por la propia Comunidad Autónoma.

En un futuro próximo será necesario arbitrar soluciones especiales para las grandes ciudades y las áreas metropolitanas españolas. Ello significa, desde medidas legislativas que impliquen la necesaria modificación de una normativa de régimen local uniformista y que no discierna entre las diversas necesidades y problemáticas de los municipios pequeños y los de las grandes ciudades; o la necesidad, en Cataluña, de que la ley de creación de las comarcas distinga, cosa que tampoco hace, entre la diversa problemática y naturaleza de las comarcas rurales y las comarcas altamente urbanizadas; pasando por los regímenes especiales -Carta municipalde las principales ciudades españolas así como la puesta en marcha 
de programas de actuación e inversión estatales y autonómicos para las grandes ciudades.

Situaciones especiales, y una gran aglomeración lo es, requieren tratamientos especiales.

\section{LA ORGANIZACIÓN DE LAS ÁREAS METROPOLITANAS}

\section{Propuestas generales}

Las grandes ciudades españolas (Madrid, Barcelona, Sevilla, Bilbao y Valencia) requieren un gobierno metropolitano fuerte que pueda recibir transferencias y recursos tanto de la Administración Central con cargo a la Participación de Tributos del Estado (PTE) como de la Administración Autonómica; debe tener importantes cometidos en materia urbanística, en promoción económica, en vivienda, en transporte y circulación y en la gestión de servicios y atribuir su valor de marca central a toda la región metropolitana.

Un gobierno de esta naturaleza sería deseable que, para tener mayor autoridad al acometer grandes realizaciones urbanas y promover la redistribución, procediera de la elección directa de los ciudadanos.

La existencia del gobierno de la ciudad metropolitana no debe anular la presencia vital y necesaria de los municipios de la ciudad real que contribuyen a dotarla de multicentralidad y polivalencia, que conservarían la mayor parte de sus competencias y que gestionarian o ejecutarían por delegación servicios y/o programas metropolitanos.

El gobierno metropolitano supone una radical descentralización del municipio central tanto por razones de eficacia como para evitar que su peso gravite sobre los demás municipios y sobre el propio gobierno metropolitano.

Este modelo, seguido por la reciente Ley Italiana sobre Áreas Metropolitanas, parece una buena fórmula para el gobierno de las grandes ciudades, si bien no parece fácilmente aplicable en nuestro país. Por una parte, la necesidad de consolidar los gobiernos de las Comunidades Autonómas y, por otra, la fuerte personalidad y capacidad de autogobierno de los municipios representan obstáculos tan legítimos como difíciles de superar.

Cualquier modelo exige por lo menos el esfuerzo de no crear, en la medida de lo posible, más estructuras político-administrativas añadidas a las existentes. El ciudadano agradecerá todo esfuerzo de simplificación administrativa y los recursos públicos, siempre tan escasos, también.

Es por ello que parece más viable plantearse una solución a dos niveles:

a) Región metropolitana o área funcional: Es la ciudad región, discontinua; es el ámbito de planeamiento territorial y estratégico y de 


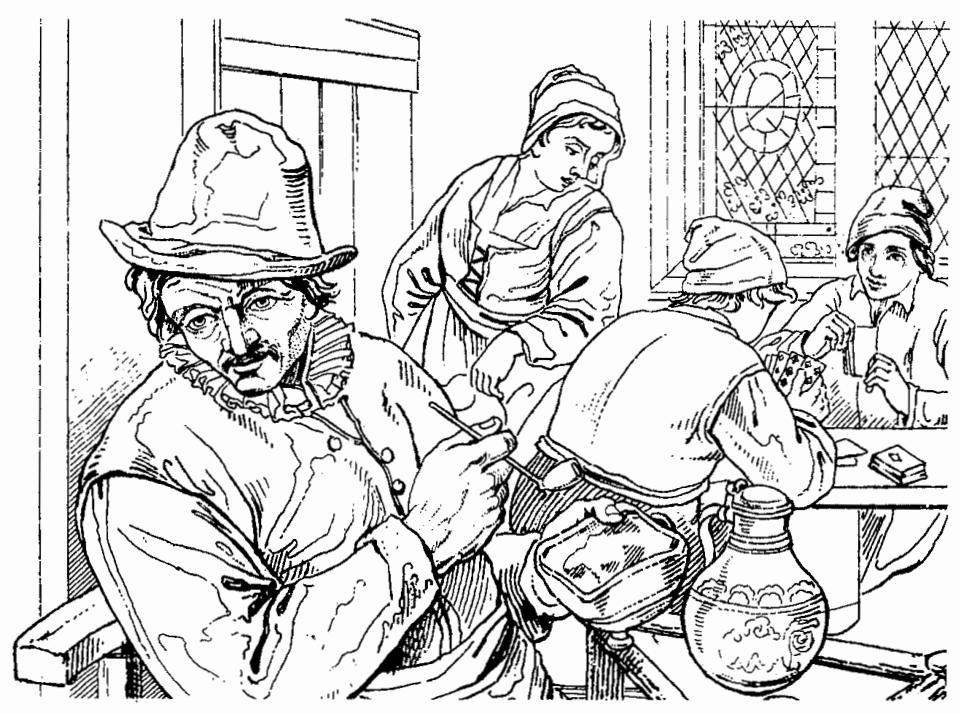

gestión de algunos servicios públicos que desbordan el marco de lá ciudad estricta: transportes y circulación básica, abastecimiento y saneamiento de agua, tratamiento y eliminación de residuos, parques tecnológicos y universidades.

En la mayoría de los casos esta región metropolitana puede estructu. rarse institucionalmente en coincidencia con la provincia, entidad local supramunicipal que, a pesar de no ser de elección directa, tiene la ventaja de ser una administración pública territorial ya existente.

Este ámbito regional es un ámbito de concertación entre la administración central, la autonómica y la local: la cooperación institucional debe hacerse mediante organismos específicos (consorcios) o por vía contractual (contratos-programa, contratos-ciudad). Esta concertación debe incluir a una gran diversiclad de instituciones políticas, así como a organismos autónomos y empresas públicas (clelegaciones ministeriales y consejerías autonómicas, universidad, puerto, acropuerto, etcétera).

Un ejemplo sobre la forma de articular la concertación puede ser la creación de un consorcio encargado de la elaboración, seguimiento y aplicación del Plan Territorial y Estratégico Regional (en sentido metropolitano) que pudiera asumir alguna de las actuaciones públicas 
fuertes y que estableciera las normas de coordinación de los planes de actuación de todos los organismos implicados.

b) Área metropolitana estricta o ciudad-real, continuo urbano o aglomeración: Es el ámbito de la gestión de los servicios supramunicipales de conformidad con los objetivos estratégicos y el planteamiento general aprobado en el ámbito regional y el de la política de reequilibrio y solidaridad intermunicipal.

Si existe la institución local de ámbito regional mencionada en el apartado anterior, dicha institución puede crear los organismos autónomos, consorcios, institutos o empresas públicas que, favoreciendo al máximo la participación de los municipios afectados, se encarguen de gestionar la prestación de los servicios en los ámbitos o subámbitos regionales adecuados.

En el supuesto de que no exista la mencionada institución local regional, puede ser adecuada la constiución de un ente local metropolitano (entidad metropolitana, mancomunidad de municipios, comarca) basado en la agrupación de municipios, para ejercer las funciones antes señaladas más todas aquellas otras que los propios municipios quieran delegarle así como para recibir transferencias (de recursos y de competencias) de la Comunidad Autónoma y del Estado.

Este ente debe tener una composición directamente proporcional a la población, garantizando la presencia en el gobierno-Consejometropolitano de todos los municipios y equilibrando en su seno el peso de la ciudad central y el de los restantes municipios de la aglomeración.

\section{Propuestas para Barcelona, ciudad metropolitana}

En el caso de Barcelona, y desde el punto de vista de la ciudad real, entendida como región metropolitana o ciudad del futuro, comprende un espacio de unos $3000 \mathrm{~km}^{2}$ y algo más de 4000000 de habitantes. Es el espacio de la movilidad cotidiana, altamente interdependiente, donde un tercio de los habitantes que no residen en la ciudad central trabajan en su propio municipio, otro tercio trabaja en el área metropolitana y el tercio restante en el municipio de Barcelona. Es el espacio mínimo indispensable para la planificación cle las infraestructuras directamente relacionadas con el desarrollo de la ciudad.

Como ejemplo de la complejidad administrativa existente, en esta región metropolitana intervienen: el Estado, la Comunidad Autónoma, la Diputación como organismo provincial, por lo menos cinco consejos comarcales, tres organismos metropolitanos y los alrededor de 70 municipios que la integran.

Un segundo ámbito territorial, el de la aglomeración o continuo urbano, está fragmentado en una treintena de municipios para sólo 500 
$\mathrm{km}^{2}$ y alrededor de 3100000 habitantes. Siguiendo con la complejidad administrativa, existen tres organismos de carácter metropolitano que no abarcan el mismo territorio. La Mancomunidad de Municipios del Área Metropolitana, de carácter voluntario e integrada por 24 municipios, se ocupa del desarrollo conjunto del urbanismo, la promoción económica y la coorclinación con las otras dos entidades metropolitanas: la del transporte, integrada por 18 municipios y la del medio ambiente, integrada por 24 municipios.

En las áreas metropolitanas vivimos una crisis de sus funciones tradicionales, como son la planificación del territorio y la gestión de servicios. Crisis en la planificación porque el territorio que comprenden es demasiado pequeño y porque las regiones han asumido gran parte de sus competencias. Crisis en la gestión de servicios porque la ciudad real es una ciudad discontinua y porque la gestión depende de los recursos de otros organismos del Estado o de la región, con los cuales es difícil aún establecer relaciones contractuales. Esta crisis de funciones no es sólo por la excesiva fragmentación o por falta de entidades metropolitanas fuertes competencial y económicamente. En las áreas metropolitanas debemos gestionar un nuevo tipo de funciones y competencias en aquello que se denomina "completar la ciudad". Normalmente, los problemas sociales se dan en mayor grado en las zonas de frontera intermunicipal de la ciudad real. Por ello es necesaria una estructura política metropolitana que permita integrar a todos los ciudadanos, que coordine los servicios que no son típicamente metropolitanos (transporte, agua, etc.), sino que tienen un carácter más local (servicios sociales, policía municipal, etcétera).

Necesitamos de un nivel metropolitano para formular un proyecto estratégico de todo el territorio que haga posible la concertación interadministrativa y la creación de una estructura política adecuada para su gestión y la coordinación de las inversiones coaligadas al plan. Sólo mediante la planificación estratégica se pude definir la ciudad y hacerla competitiva en la Europa de 1993. Pero el objetivo principal del plan estratégico debe ser asegurar la calidad de vida en la ciudad. No es cicrto o, mejor, no podemos admitir que exista una contradicción entre caliclad de vida y desarrollo económico. Si el desarrollo supone sacrificar la calidad de vida, fracasa a medio plazo porque la ciudad pierde su atractivo, se hace insegura, inhabitable, etcétera.

En definitiva, nuestra propuesta de futuro es la de institucionalizar la región metropolitana como sustitución de la actual provincia, no sólo porque el territorio de la provincia no tiene mucho sentido, sino porque la región metropolitana siempre ha estado legitimada. Esta propuesta significa dividir la actual provincia de Barcelona en dos.

De inmediato, y basándose en el caso de Barcelona, debería establecerse: 
a) División en dos de la actual provincia de Barcelona de forma que se constituya una quinta provincia en Cataluña que agrupe la región metropolitana de Barcelona (comprensiva de las comarcas del Baix Llobregat, el Barcelonés, el Maresme, el Vallés Occidental y el Vallés Oriental).

b) Modificación de las leyes de ordenación territorial de Cataluña dando carácter de entidad local a las regiones. Creación de cinco entes regionales con un ámbito territorial coincidente con el de las cinco provincias catalanas.

c) Creación por parte de la región metropolitana de Barcelona de aquellas instituciones (organismos autónomos, empresas públicas o mixtas, consorcios, etc.) de ámbito regional, comarcal y subregional adecuadas para la realización de las actuaciones y la prestación de servicios públicos de carácter metropolitano.

d) Considerando que los municipios de la región metropolitana de Barcelona constituyen una única entidad local, representada precisamente por el ente regional, a efectos del cálculo de las transferencias del Estado (participación de tributos del Estado) y de la Comunidad Autónoma.

e) Impulso y creación por parte de la región metropolitana de Barcelona de un Consorcio con la Administración Central y la Generalitat de Catalunya para la elaboración, revisión, modificación y gestión del Plan Territorial y Estratégico Regional, el cual podía dictar normas de coordinación de los planes de actuación anual y/o plurianual de los entes dependientes de las instituciones que componen el consorcio.

f) Impulso y creación por parte de la región metropolitana de Barcelona de consorcios con la Administración Central y la autonómica para la planificación y la gestión sectorial regional conjunta de conformidad con las normas del Plan Territorial y Estratégico antes mencionado (básicamente en materia de agua, transporte y grandes infraestructuras: aeropuerto, puerto, feria, TAV, etc). En dichos consorcios deberían estar representados también los organismos autónomos o empresas públicas implicados.

\section{CONCLUSIONES}

En conclusión debemos afirmar que las grandes ciudades requieren dotarse del marco adecuado para su buen gobierno y funcionamiento. No olvidemos que estamos inmersos en un periodo de crecimiento y por tanto de desequilibrios y tensiones en el territorio que van a exigir grandes actuaciones y nuevos servicios públicos o público-privados.

Este marco político administrativo debe necesariamente gozar del consenso institucional entre las administraciones central, autonómica y 
local. No en vano, la gran ciudad es, por su naturaleza y su papel, una cuestión de Estado.

Precisamente por esto, también es un tema que afecta a las organizaciones económicas y sociales. Hoy en día la legitimidad de los votos emitidos cada cuatro años para el buen gobierno de la ciudad, no es suficiente. Es preciso instrumentar mecanismos de participación y cooperación públicoprivada como una constante en la toma de decisiones de la gran ciuclad.

En otro orden de cosas, la estructura de gobierno de la misma debe encontrar su encaje, en la medida de lo posible, entre las administraciones locales existentes para no provocar superposiciones innecesarias de nuevos niveles administrativos y para gozar de transparencia y legitimidad democrática.

En cualquier caso, ni el gobicrno local, ni el Estado, ni la Comunidad Autónoma pueden olvidar que la gran ciudad metropolitana debe actuar hoy en un contexto internacional muy competitivo y que su valor en este mercado depende en gran medida de que pueda generar una representación fuerte, de que sea un interlocutor válido en el contexto europeo y de que sea capaz de garantizar un eficaz gobierno del territorio. Las grandes ciudades, con sus difíciles, pero enormes y múltiples valores de uso y con su disputado valor de cambio, son nuestros buques insignia para navegar en las concurridas aguas europeas. No nos podemos permitir que por falta de capitán adecuado vayan a la deriva.

Por último, quisiera hacer siete breves reflexiones sobre lo que considero que son falsas alternativas en el momento de discutir el programa para la ciudad metropolitana.

En primer lugar, se habla mucho sobre cuáles son las grandes ciudades en Europa, utilizando el modelo de ciudad global tipo Nueva York o Tokio. Este modelo no es aplicable al caso europeo, donde unas 40 grandes ciudades integran su sistema urbano y muchas ciudades intermedias juegan un papel de centralidad y dinamismo muy importante por razones culturales, de innovación tecnológica, por ser el centro de una región desarrollada, etc. Tampoco la concurrencia entre ciuclades es el único elemento que se da en el territorio. Es aún más importante la complementariedad que se da en su sistema urbano, las redes de intercambio, etc., especialmente para negociar ante los gobiernos nacionales y la Comunidad Europea.

Segundo: en Europa coexisten las regiones históricas, con personaliclad política y administrativa, junto a nuevas regiones emergentes: son las macrorregiones o regiones transfronterizas. Las regiones históricas, constituidas en el interior de los Estados, tienen un papel importante en la redistribución social promovida por la comunidad. Pero desde el punto de vista del desarrollo, es evidente que se están formando regiones 
más grandes, más allá de las fronteras, que establecen fuertes vínculos funcionales en su interior.

Tercero: el dilema entre área metropolitana pequeña o grande, es decir, área metropolitana-región o área metropolitana-aglomeración. Creo que son dos ámbitos complementarios. Hoy precisamos de la ciudad-región como institución supramunicipal de planeamiento estratégico y territorial y como ámbito de actuación consorciada con la región y el Estado. Y no podemos obviar el hecho de la ciudad-rcal o continuo urbano que requiere una fuerte cooperación intermunicipal en urbanismo y prestación de algunos servicios.

Cuarto: la política de servicios o política de desarrollo. Ahora que vivimos una etapa de crecimiento económico (no sólo demográfico, sino de movilidad, de intensificación de los usos múltiples del territorio), se vuelve a dar importancia a las vicjas competencias de urbanismo y de prestación de servicios.

Quinto: la prioriclad de convertir en actividad pública la administración o gestión empresarial privatizada, de dicha política. Sobre este aspecto, creo que el papel de la administración debe estar más presente en la definición de los servicios que en su gestión. Por otra parte, esta definición no se puede realizar exclusivamente desde una administración, sino en concierto mediante organismos o acuerdos interadministrativos.

Sexto: ¿cuál es el núcleo principal de la ciudad-región, el propio sistema urbano o la ciudad-central? Aun sin una respuesta exacta a este dilema, lo que parece seguro es que la ciudad-región precisa de un leadersbip personalizado, de un valor de marca que la hace más competitiva en el exterior. Este valor de marca va asociado al nombre y a la imagen del área central.

Por último, la falsa alternativa sobre el papel interior de la ciudad (integradora, de prestación de scrvicios, etc.) o de protagonismo hacia el exterior e internacionalización. La ciuclad juega un papel de concertación en el desarrollo económico que lc otorga una presencia importante en el exterior pero, al mismo tiempo, tiene también un papel muy importante en la integración de su población: hacer que sus habitantes sean plenamente ciudadanos. Por este papel interno, de servicio, no se puede privilegiar exclusivamente su carrera en la concurrencia internacional. 